\title{
Power loss analysis in altered tooth-sum spur gearing
}

\author{
Sachidananda H. K. ${ }^{1 *}$, Raghunandana $K .^{2}$ and Shivamurthy $B .{ }^{3}$ \\ ${ }^{1}$ Department of Mechanical Engineering, School of Engineering and IT, Manipal University, Dubai, UAE. \\ ${ }^{2}$ Department of Mechatronics Engineering, Manipal Institute of Technology, Manipal Academy of Higher \\ Education, Manipal-576104, India. \\ ${ }^{3}$ Department of Mechanical and Manufacturing Engineering, Manipal Institute of Technology, Manipal \\ Academy of Higher Education, Manipal-576104, India.
}

\begin{abstract}
The main cause of power loss or dissipation of heat in case of meshed gears is due to friction existing between gear tooth mesh and is a major concern in low rotational speed gears, whereas in case of high operating speed the power loss taking place due to compression of air-lubricant mixture (churning losses) and windage losses due to aerodynamic trial of air lubricant mixture which controls the total efficiency needs to be considered. Therefore, in order to improve mechanical efficiency it is necessary for gear designer during gear tooth optimization to consider these energy losses. In this research paper the power loss analysis for a tooth-sum of 100 altered by $\pm 4 \%$ operating between a specified center distance is considered. The results show that negative altered tooth-sum gearing performs better as compared to standard and positive altered tooth-sum gearing.
\end{abstract}

Keywords: Altered tooth-sum gearing, Power loss, Standard gearing, Churning losses, Windage losses.

\section{Introduction}

The windage power loss due to aerodynamic trial of air lubricant mixture is one of the important aspects which need to be considered in gear transmission systems at high speeds during optimization of gear tooth shape. In this context Fakher chaari et al., [1] have studied the windage power loss in spur gear sets and they concluded that windage power loss is a complex phenomenon and depends upon rotational speed, shape of tooth, number of tooth and module. The windage power loss using parametric modelling has been studied by satya seetharaman et al., [2]. According to them the windage power loss occurs due to interaction of gears with air-oil mixture and squeezing of the lubricant at gear mesh interface. The efficiency of the vehicle transmission system considering churning loss, bearing loss and windage loss on spur gear was studied by Wang et al., [3] using analytical and experimental results. They concluded that the losses estimated using analytical equations was in line with experimental results. The overall

* Corresponding author: sachidananda6@gmail.com 
efficiency in multistage gear train has been studied by James kuria et al., [4]. They developed a mathematical model in order to determine efficiency considering lubricant, surface finish and operating conditions and concluded that sliding friction, rolling friction and windage losses are the main source of power loss in gearing.

While gear are in mesh the gears rolls and slides and the power loss taking place during this process is termed as sliding power loss. Chakri yenti et al., [5] have studied empirical formulae for friction coefficient considering gear module, pressure angle and gear ratio. They concluded using experimental analysis that sliding power loss are more in gears having larger module as compared to smaller module. Also, larger pressure angle have lower sliding losses as compared to smaller pressure angle. Franco concli et al., [6] have studied oil squeezing power loss in spur gears. According to them efficiency is more concerned in design of power transmission and they concluded that the power loss increases with gear rotational speed. The analytical expression of efficiency of standard and high contact ratio gears has been studied by Miguel pleguezuelos et al., [7]. According to them the friction coefficient varies along the length of path of contact due to sliding and the average values of friction coefficient needs to be considered during numerical calculations. Chang et al., [8] have studied meshing losses in high load and high speed involute gears considering gear module, pressure angle, addendum height, thermal conductivity and lubricant pressure and they concluded that these parameters have significant effect on gear meshing process. The theoretical gear power loss considering density, viscosity and speed have been studied and compared using experiment by vijay kumar et al., [9] and they concluded that these parameters influence power loss significantly.

The influence of pressure angle and number of teeth variation on mechanical efficiency during varying teeth pairs in contact have been studied by chaari et al., [10] considering internal loss coefficient during rolling and sliding of gears. The power loss due to trapping and squeezing of an incompressible fluid between meshing of gear teeth have been studied by Abdelilah et al., [11]. They concluded that the rotational speed has an influence on meshing time and the operating trapped fluid. Fernandes [12] have studied load distribution along the length of path of contact to estimate gear loss factor and its influence on power loss prediction and concluded that the classical formulas are accurate in some specific condition. Luis magalhaes et al., [13] have studied influence of tooth profile and oil formation on power loss. They concluded that the friction losses need to be reduced to improve lower energy consumption, lower operating temperature and lower risk of failures.

\section{Methodology}

\subsection{Estimation of power loss.}

The amount of power loss during gear tooth mesh depends upon type of gear tooth, characteristics of gear tooth engagement and coefficient of friction during mesh. The amount of power loss during transmission occurs due to sliding, rolling, formation of elasto-hydrodynamic film, windage and churning losses. During gear tooth mesh as the load is continuously changing the power loss due to sliding plays an important role. The power loss in case of gears is influenced by angular velocity, ratio of rolling velocities, point of contact, contact ratio and lubricant properties. Sliding friction depends upon sliding velocity and friction force which in turn depends upon tooth load and instantaneous coefficient of friction. In this research paper the sliding power loss and coefficient of friction along the length of path of contact has been taken into consideration. Also, the efficiency is calculated based on the power loss due to sliding. Benedict and Kelly $[14,15]$, developed a model considering coefficient of friction along the path of contact, tooth load, sliding velocity, tangential velocity and lubricant viscosity to find sliding power loss as shown in equation (1) and (2). 
Coefficient of friction along the path of contact

$F S \#=0.0127 \log _{10}\left(29.66\left(\frac{W \#}{\vartheta}\right) V_{s} \#\left(V_{t \#}^{2}\right)\right)$

Sliding power loss along the path of contact

$P S \#=\frac{F S \# \times V_{S} \# \times W \# \times 10^{-3}}{\cos \left(\tan \frac{(T \#)}{R_{b}}\right)}$

Efficiency considering sliding power loss

Efficiency $=1-\left(\frac{\text { Total power loss per mesh }}{\text { Power transmitted }}\right) \times 100$

Where, FS is coefficient of friction, $\mathrm{W}$ is the tooth load, $v$ is the viscosity of the oil, $\mathrm{V}_{\mathrm{S}}$ is sliding velocity, $V_{t}$ is the tangential velocity, $P S$ is sliding power loss, $R_{b}$ is the base circle radius of pinion, \# is different points along length of path of contact as A, B, D and E.

In this power loss analysis both the gears are made of steel $\mathrm{C}-40, \mathrm{v}=0.3, \mathrm{E}=200 \mathrm{GPa}$, module of $2 \mathrm{~mm}$, pressure angle of $20^{\circ}$ (lower range), $25^{\circ}$ (higher range) and tangential tooth load of 10 $\mathrm{N}$ per unit millimeter of face width is considered for computation. Based on the above model the power loss along length of path of contact due to sliding is computed for altered tooth-sum of 100 $\pm 4 \%$ at different points $\mathrm{A}, \mathrm{B}, \mathrm{D}$ and $\mathrm{E}$ along the length of path of contact.

\section{Results and discussion}

By using Benedict and Kelly models a C-program has been developed based on the methodology to estimate sliding power loss of the spur gear tooth for various values of profile shift for a fixed center distance for altered tooth-sum gearing (100 by $\pm 4 \%$ ). Fig. 1(a) shows the plot of power loss versus profile shift for a 96 tooth-sum meshed gear system. It is observed from the plot that the power loss at point $\mathrm{A}, \mathrm{B}, \mathrm{D}$ and point $\mathrm{E}$ are 2.17 watts, 3.40 watts, 0.2 watts and 0.17 watts respectively for profile shift $\mathrm{X}_{1}=0.4$ on pinion. The power loss at point $\mathrm{A}$ and $\mathrm{B}$ decreases continuously as the values of profile shift increases due to reduction in contact friction. Similarly, the power loss at point $\mathrm{D}$ and $\mathrm{E}$ increases continuously as the value of profile shift increases due to increased contact friction. However, at point $\mathrm{A}$ and $\mathrm{B}$ friction is more as compared to point $\mathrm{D}$ and $\mathrm{E}$. Hence the power loss is more at these two points.

Similarly, it is observed that for a range of tooth-sums $100 \pm 4 \%$, the power loss decreases at point $A$ and $B$ and increases at point $D$ and $E$ for various values of profile shift coefficient on pinion (Fig. 1(a) to Fig. 1(c)). It is observed that the power loss for profile shift $\mathrm{X}_{1}=-0.1$ at point $\mathrm{E}$ is zero watts (ideal case) for tooth-sum of 97 due to very small sliding distance (E to $\mathrm{C}$ ) which in turn low sliding velocity. This leads to lower friction and lower power loss. From this it is evident that power loss depends on sliding distance, sliding velocity and friction force. Also, it is observed that sliding velocity depends upon normal tooth load and instantaneous coefficient of friction.

However, it is noticed that not much variation of power loss in case of negative alteration (96), standard (100) and positive alteration (104) in tooth-sum gearing. Also, the power loss at different points along the length of path of contact remains approximately the same for various values of profile shift on pinion. 

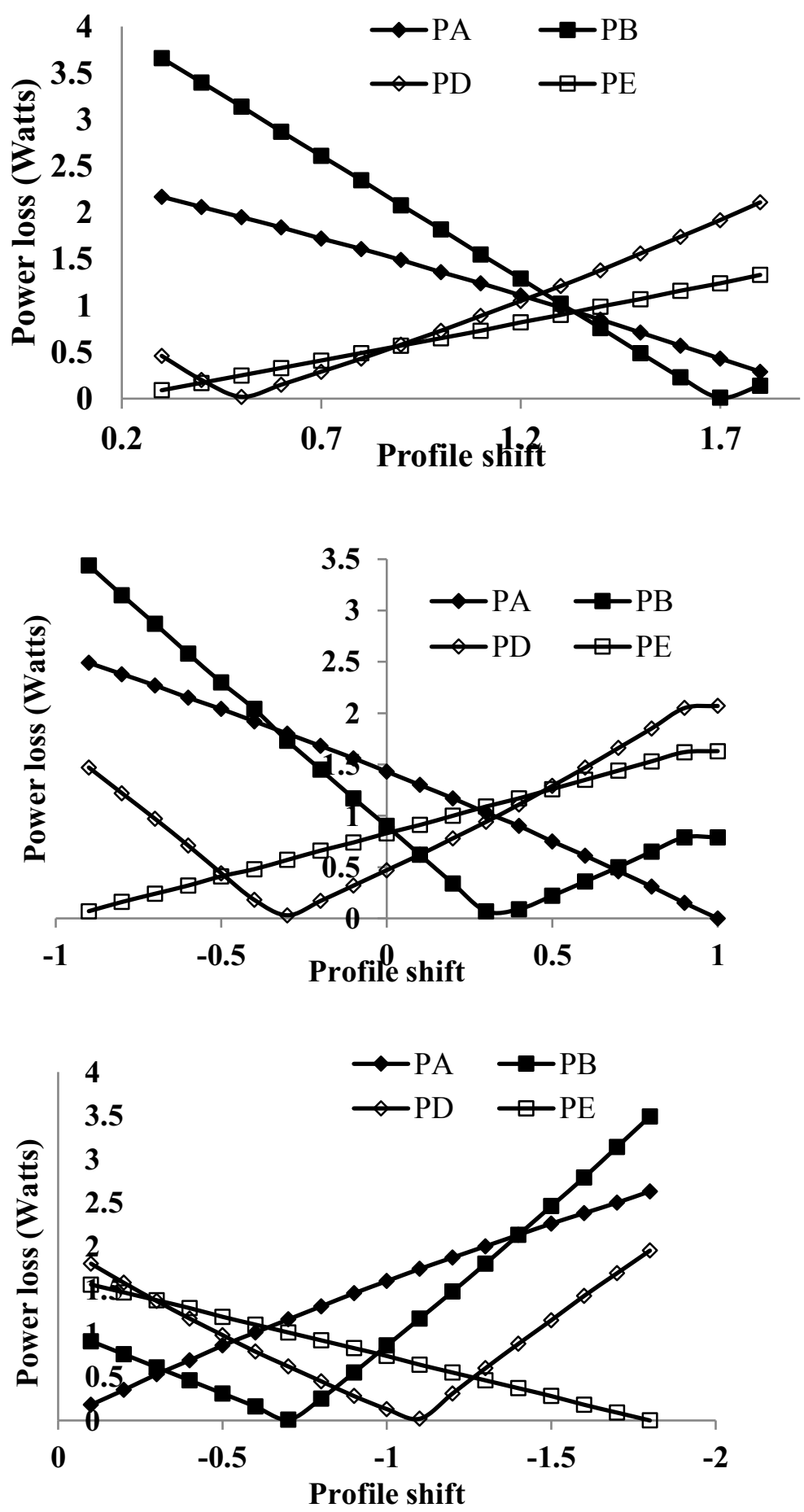

Fig. 1. Plot of power loss versus profile shift along the length of path of contact for higher range of pressure angle: a) 96 tooth-sum b) 100 tooth-sum c) 104 tooth-sum 

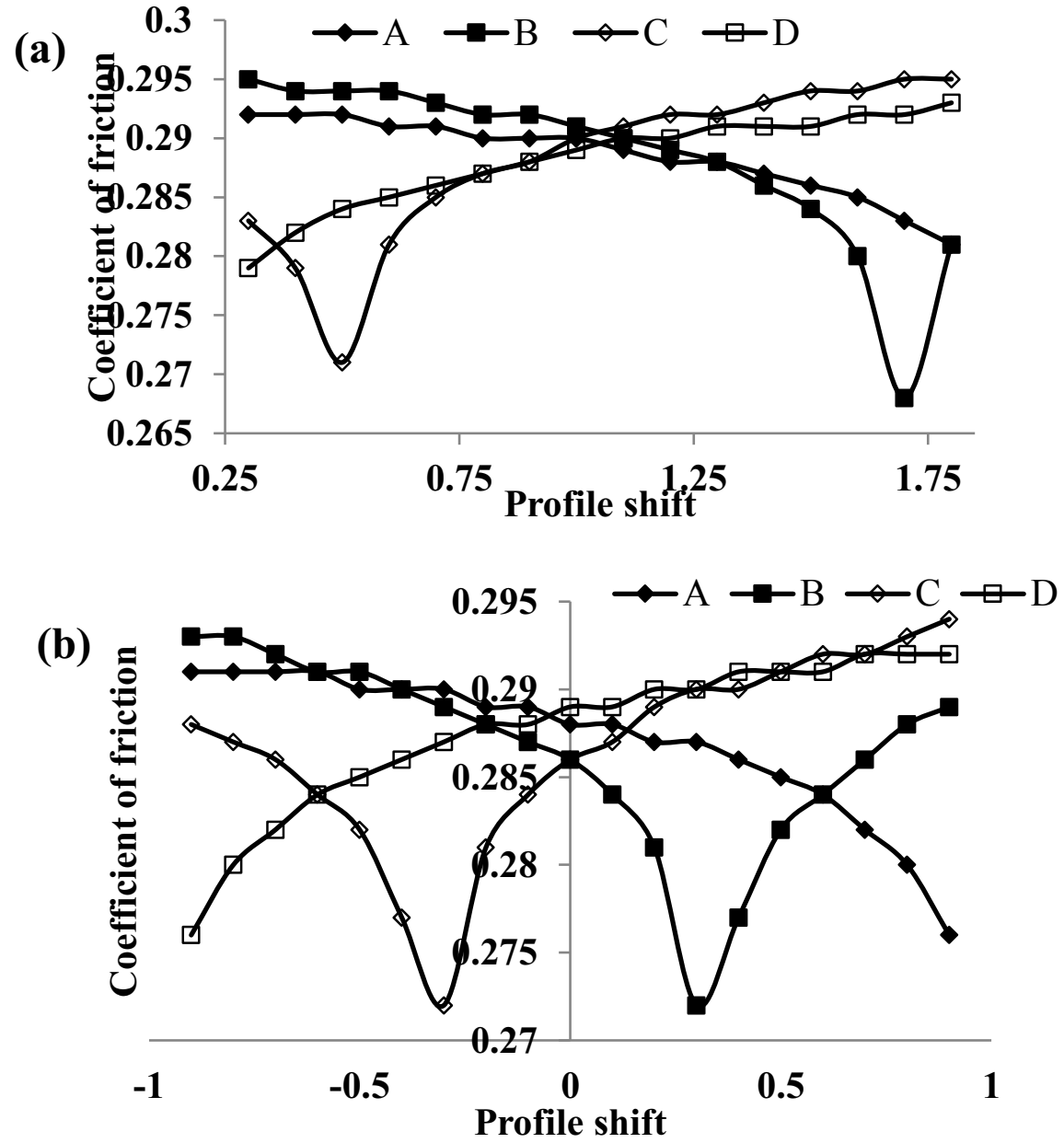

(c)

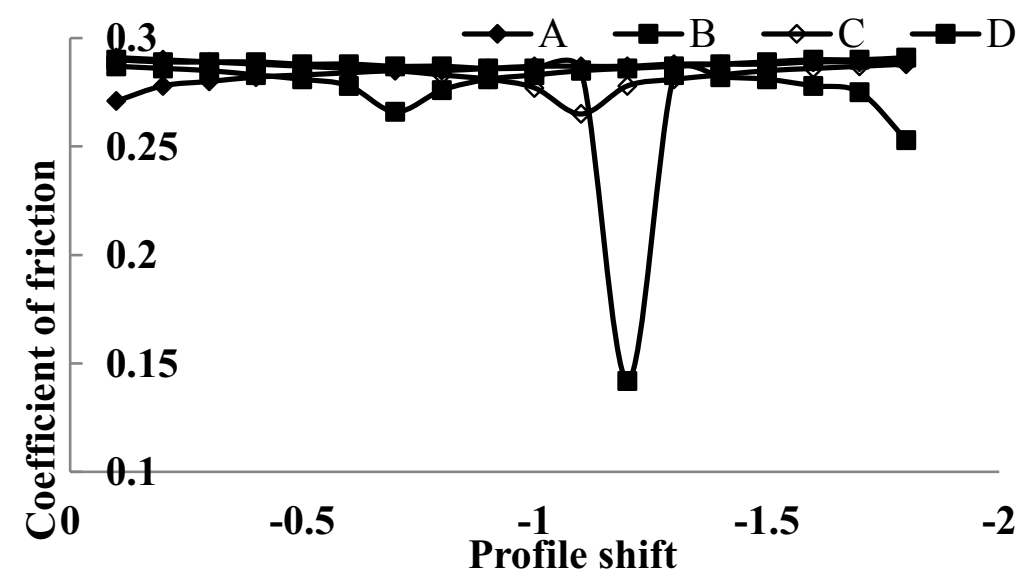

Fig. 2. Plot of coefficient of friction versus profile shift along the length of path of contact for higher range of pressure angle: a) 96 tooth-sum b) 100 tooth-sum c) 104 tooth-sum. 
Table 1. Power loss and coefficient of friction for 96,100 and 104 tooth-sum at point A, point B, point D and point $\mathrm{E}$ for higher range of pressure angle.

\begin{tabular}{|c|l|c|c|c|c|}
\hline Profile shift & 96 tooth-sum & $\begin{array}{c}\text { Point } \\
\text { A }\end{array}$ & Point B & Point D & Point E \\
\hline \multirow{3}{*}{$\mathbf{0 . 4}$} & Power loss(Watts) & 2.17 & 3.40 & 0.2 & 0.17 \\
\cline { 2 - 6 } Profile shift & Friction coefficient & 0.292 & 0.294 & 0.279 & 0.282 \\
\hline \multirow{3}{*}{$\mathbf{0 . 4}$} & 100 tooth-sum & Point A & Point B & Point D & Point E \\
\cline { 2 - 6 } Profile shift & Power loss(Watts) & 0.91 & 2.25 & 2.99 & 0.23 \\
\hline \multirow{3}{*}{$\mathbf{- 0 . 4}$} & 104 tooth-sum & Point A & Point B & Point D & Point E \\
\cline { 2 - 6 } & Power loss(Watts) & 0.69 & 0.46 & 1.17 & 1.29 \\
\hline
\end{tabular}

Fig. 2 (a) shows the plot of coefficient of friction versus profile shift for 96 tooth-sum gearing (higher range of pressure angle). It is noticed that, the coefficient of friction decreases at point A and B and increases at point $\mathrm{D}$ and $\mathrm{E}$ for various profile shift. Similar trend was observed in 100 and 104 tooth-sum gearing (Fig. 2 (b) and Fig. 2 (c)). The power loss and coefficient of friction for 0.4 profile shift for altered tooth-sum gearing and standard gearing is tabulated in Table 1. From this Table 1 it is observed that for positive profile shift the total power loss is more as compared to negative profile shift and occurs due to pressure gradient difference [1]. It is also noticed from the tabulated values that the coefficient of friction is slightly higher for 96 tooth-sum as compared to 100 and 104 tooth-sum.

\subsection{Power loss, film thickness and specific film thickness using KISSSOFT ${ }^{\circledR}$}

KISSsoft ${ }^{\circledR}$ is the commonly used software by gear designers for strength analysis of gears which are used in construction equipment, cable car transmissions, mars rovers etc. The strength analysis of gears by KISSsoft ${ }^{\circledR}$ is based on ISO, AGMA and DIN standards. In addition to the strength analysis, it also includes design and optimization. In order to compare the power loss, negative altered tooth-sum gearing (96 tooth-sum) and standard tooth-sum gearing (100 toothsum) have been considered. The analysis of power loss, film thickness and specific film thickness has been compared using KISSOSFT ${ }^{\circledR}$ for the above tooth-sum. Fig. 3 shows the plot of power loss versus angle of rotation for 96 tooth-sum for different points along length of path of contact for profile shift of 0.3 . From this it is observed that the power loss at point A is 0.32 watts per unit $\mathrm{mm}$ of face width. Also, from the graph it is observed that the power loss at point $\mathrm{C}$ (pitch point) is zero and occurs due to pure rolling. The power loss at end point of contact is 0.04 watts per unit $\mathrm{mm}$. From this it can be concluded that the power loss reduces from point B (HPTSC) continously upto pitch point $\mathrm{C}$ and it slightly increases from point $\mathrm{C}$ to end point of contact. Similarly, Fig. 4 shows the plot of film thickness versus angle of rotation for 96 tooth-sum. From this plot it is observed that the film thickness at initial point of contact $\mathrm{A}$ is $0.79 \mu \mathrm{m}$ and reduces at point B (HPSTC) and slightly increases from point B to point D and again slightly increases from point $\mathrm{D}$ to end point of contact (point $\mathrm{E}$ ). The film thickness at point $\mathrm{B}$ (HPSTC) and point D (LPSTC) approximately remains constant at these two points and the film thickness is lesser compared to other points of contact. These are the two critical points during gear teeth mesh as the load is carried by only one pairs of teeth during this region and more chances of crack propogation occurs at these points of contact.

Fig. 5 shows the specific film thickness versus angle of rotation for 96 tooth-sum at different points along the length of path of contact. Specific film thickness ratio is the ratio of lubrication oil film thickness to the combined roughness and is also termed as lambda ratio $(\lambda)$. Using specific film thickness, it is possible to identify whether the lubrication condition occuring during gear teeth mesh can be full film or EHD, mixed wear lubrication and boundary lubrication. If the specific film thickness ratio lies above 3 then the lubrication occuring between the gear teeth is 
full film or EHD lubrication and the contact between the asperities is negligible which in turn friction and wear is less. Similarly, if the specific film thickness ratio is between 1.4 and 3 then the lubrication maintained between the gear teeth is mixed wear lubrication and under these circumstances some contact will takes place between the asperities and friction and wear will be more [16]. If the film thickness ratio is less than 1.4 then the lubrication maintained between the gear teeth is boundary lubrication and severe wear [17].

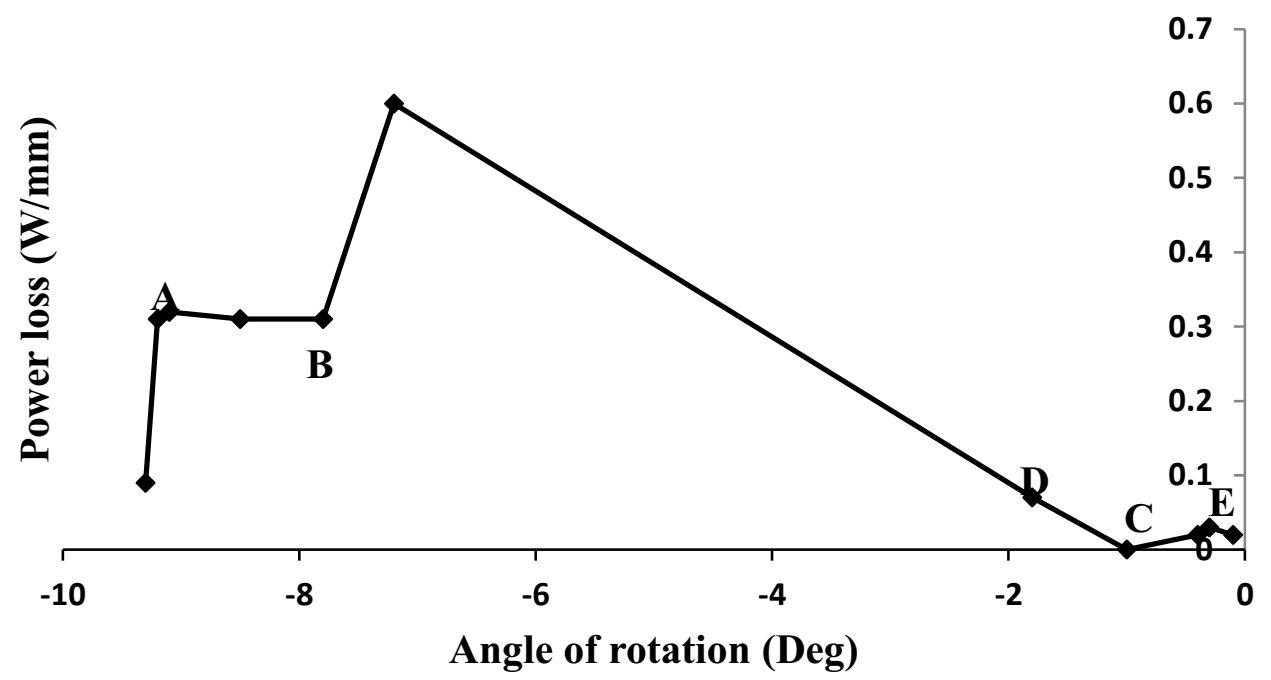

Fig. 3. Plot of power loss versus angle of rotation (Deg) for 96 tooth-sum

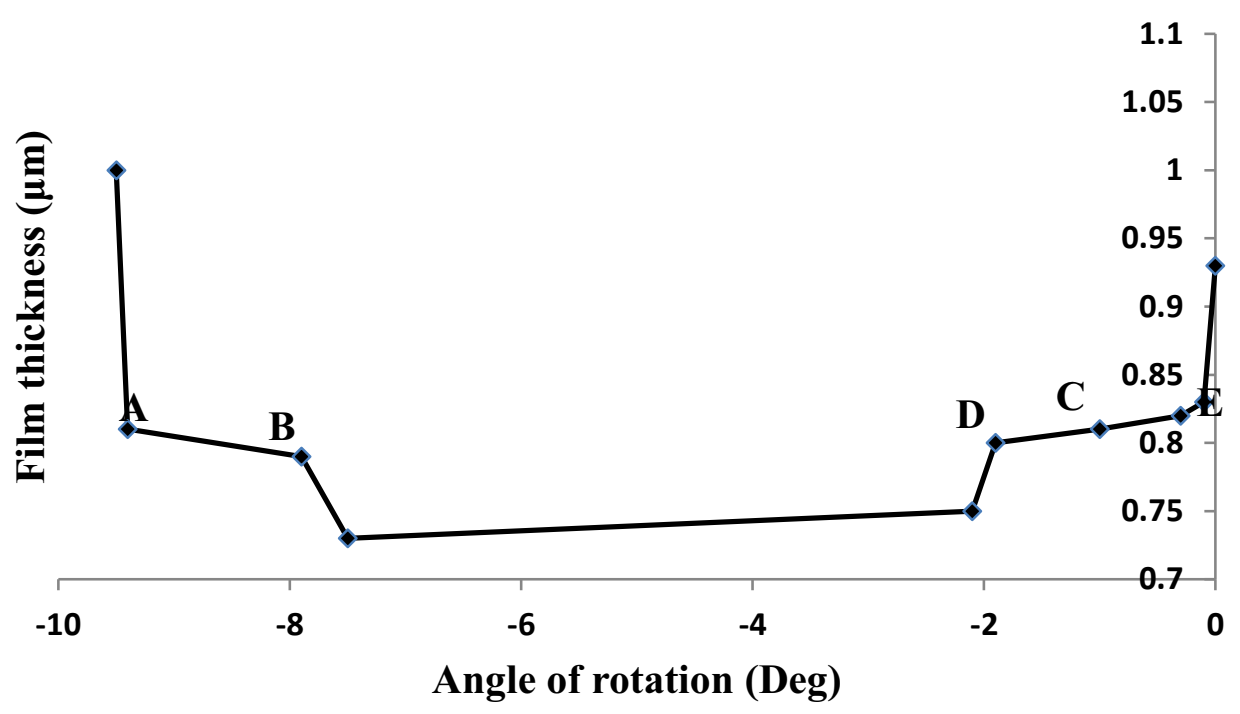

Fig. 4. Plot of film thickness versus angle of rotation (Deg) for 96 tooth-sum

Fig. 6 to Fig. 8 shows the plots of power loss, film thickness and specific film thickness for 100 tooth-sum for various angle of rotation of pinion. The analysis for power loss, film thickness and specific film thickness performs in the same way as discussed above for 96 tooth-sum. 
As a power loss comparison for 96 tooth-sum and 100 tooth-sum from Fig. 3 and Fig. 6. It is observed that the angle of rotation in case of 96 tooth-sum will vary from -9.2 degrees to 0.1 degree whereas in case of 100 tooth-sum the angle of rotation will vary from -6.2 to 5.1 degrees. From Fig. 3, it is observed that the power loss continuously decreases from point B (LPSTC) to point D (HPSTC) for 96 tooth-sum whereas in case of 100 tooth-sum the power loss increases from point B (LPSTC) and then slightly decreases up to point D (HPSTC). From this it is observed that the power loss approximately decreases in case of 96 tooth-sum, whereas it behaves abruptly in case of 100 tooth-sum at different points along the length of path of contact. The power loss per unit mm in case of 96 tooth-sum is lesser as compared to that of 100 tooth-sum at initial point of contact and end of point of contact. Similarly, the film thickness in case of 96 tooth-sum is more as compared to that of 100 tooth-sum. From this it can be concluded that 96 tooth-sum have greater resistance to the damage to fatigue stresses and the process of damage is delayed as compared to 100 tooth-sum [18]. Also, it is observed that the specific film thickness ratio is more in case of 96 tooth-sum as compared to 100 tooth-sum. This shows that the service life of the gearing in case of 96 tooth-sum is more as compared to 100 tooth-sum.

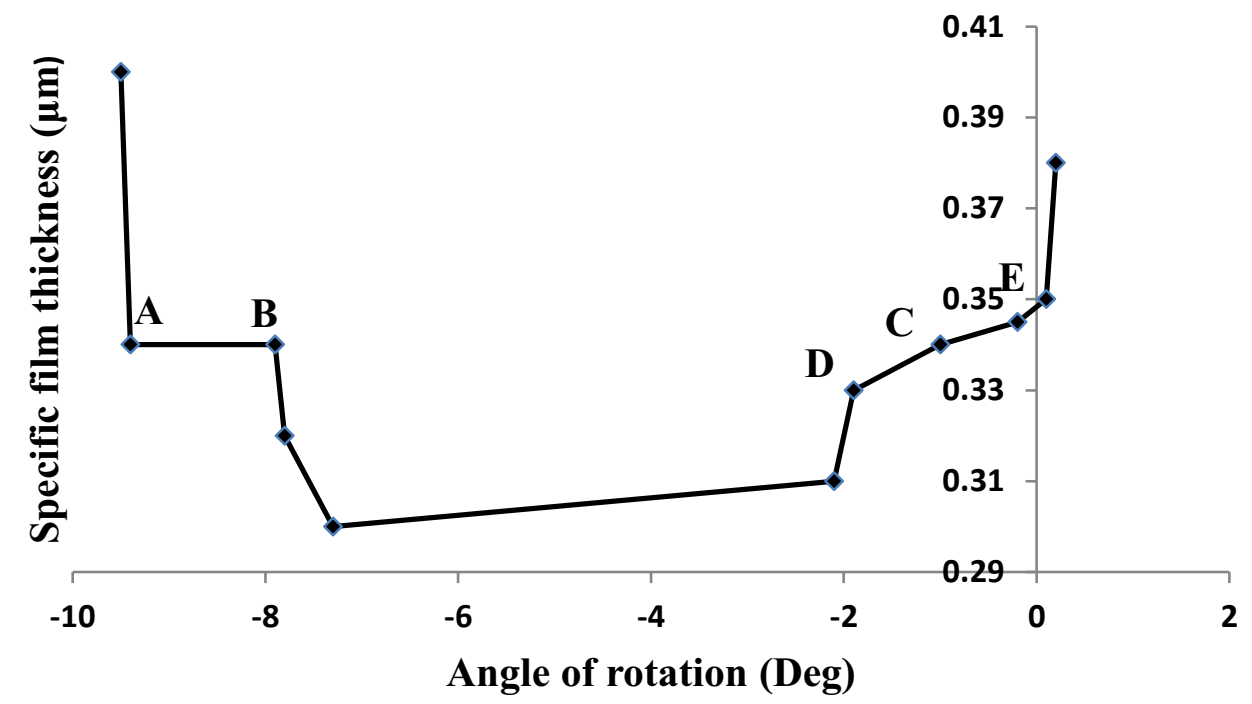

Fig. 5. Plot of specific film thickness versus angle of rotation (Deg) for 96 tooth-sum 


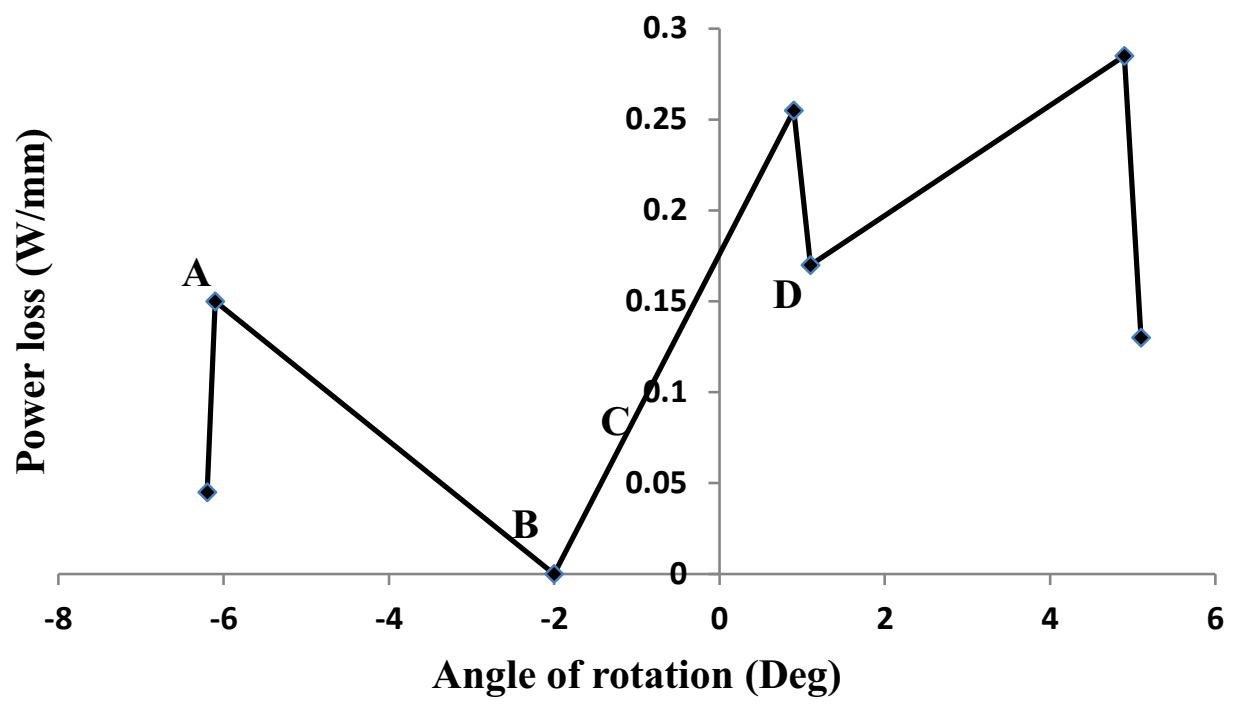

Fig. 6. Plot of power loss versus angle of rotation (Deg) for 100 tooth-sum

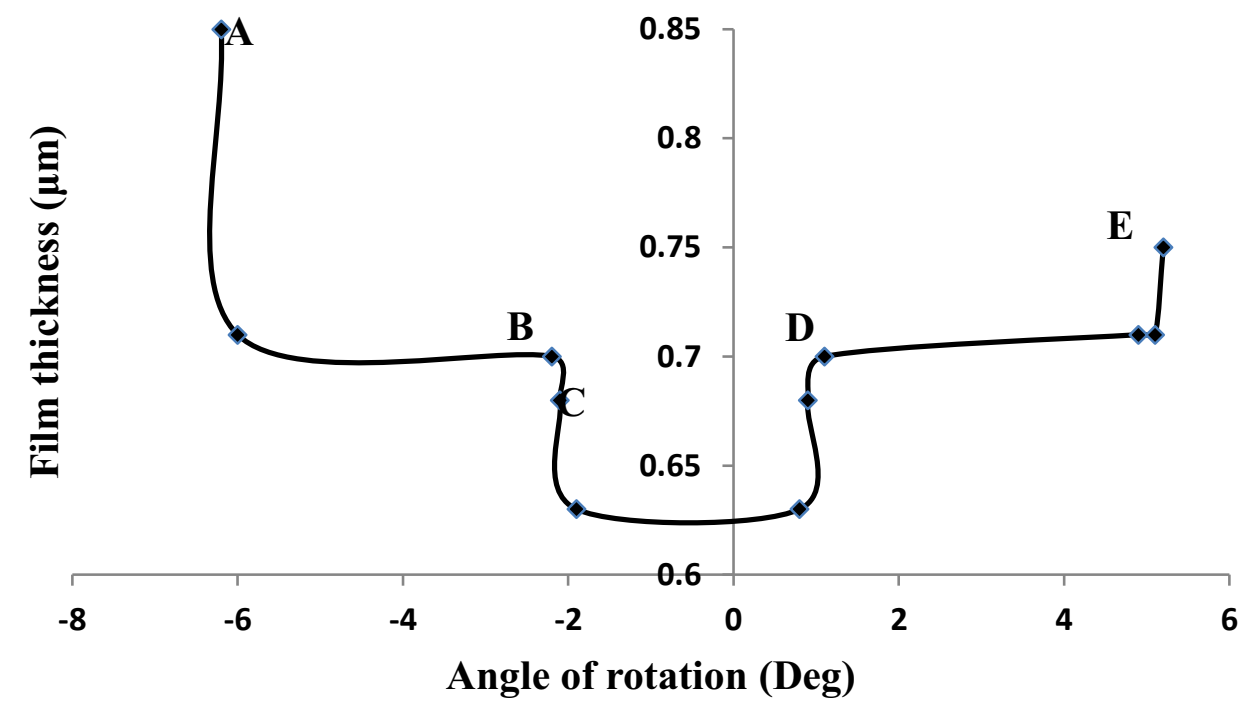

Fig. 7. Plot of film thickness versus angle of rotation (Deg) for 100 tooth-sum 


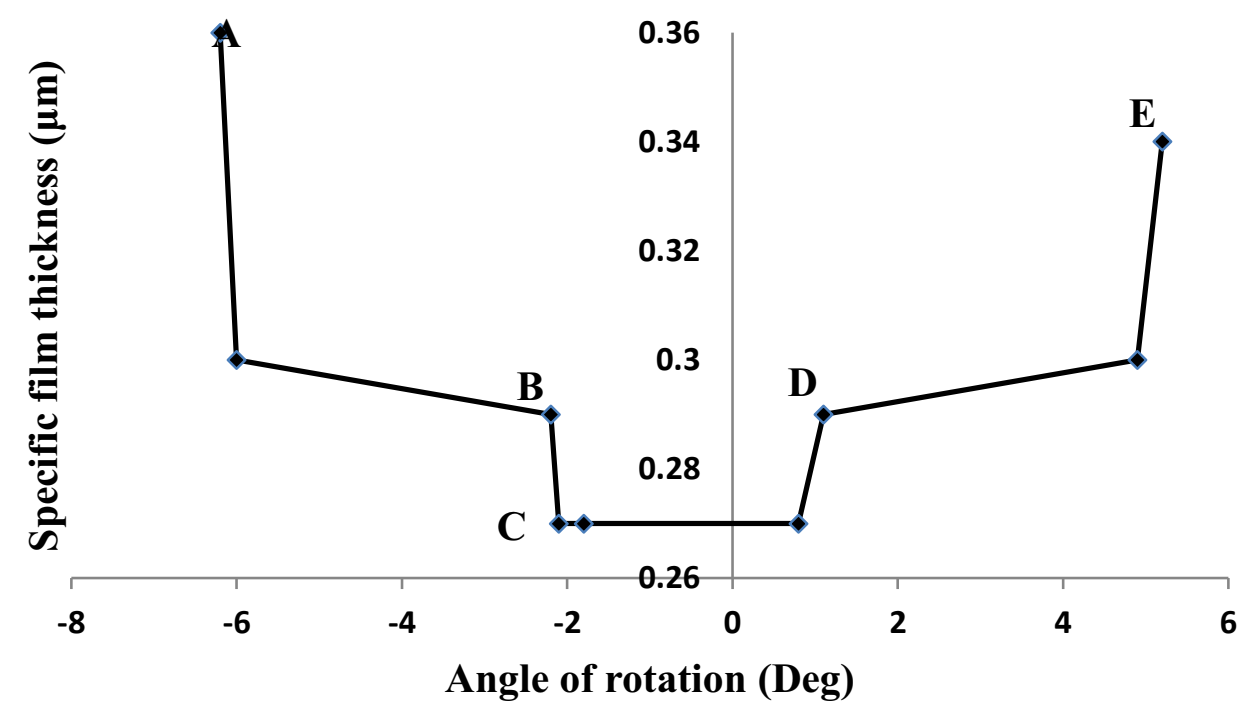

Fig. 8. Plot of specific film thickness versus angle of rotation (Deg) for 100 tooth-sum

\subsection{Comparison of percentage change in power loss for higher and lower range of pressure angle.}

In case of 96 tooth-sums the profile shift will vary from 0.3 to 1.8. But, in case of 100 tooth-sums the profile shift will vary from -0.9 to 0.9 . An attempt is made to compare the power loss in common profile shift (between 0.3 to 1 ) of both altered tooth-sum gearing and standard gearing. It is noticed that the power loss is directly proportional to profile shift (Fig. 9 (a)). At point A negative alteration in tooth-sums has 2.73 times less power loss as compared to standard toothsum gearing. Similarly, negative altered tooth-sum gearing at different points B, D and E the power loss is 14.26, 11.28 and 4.01 times compared to standard tooth-sums gearing. The percentage changes in power loss of positive altered tooth-sum gearing at different points along A, B, D and E will be 2.29, 36.6, 0.25 and 3.17 times lesser as compared to standard tooth-sum gearing. 

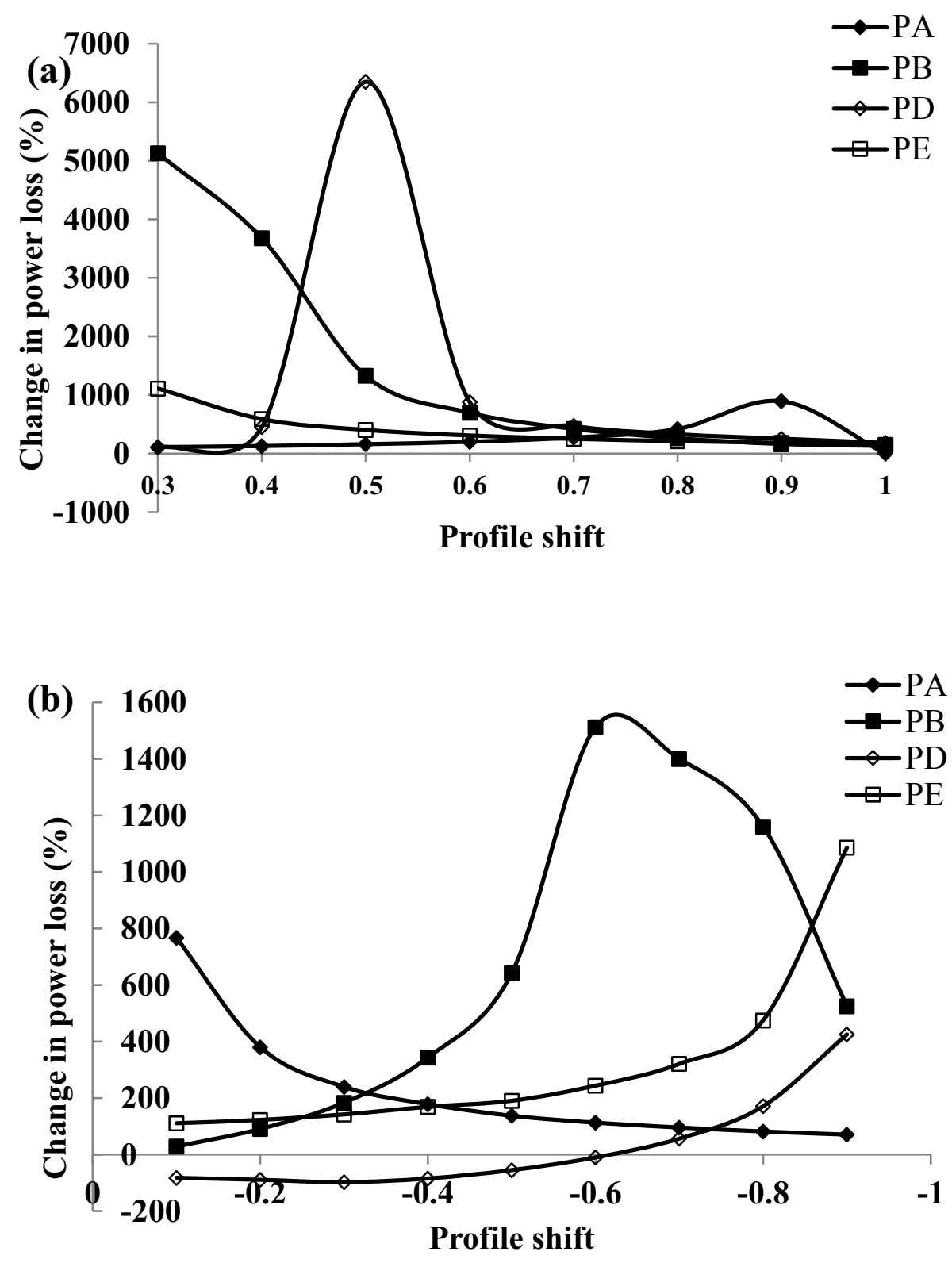

Fig. 9. Plot of percentage change in power loss along length of path of contact for higher range of pressure angle: a) 96 and 100 tooth-sum b) 100 and 104 tooth-sum. 

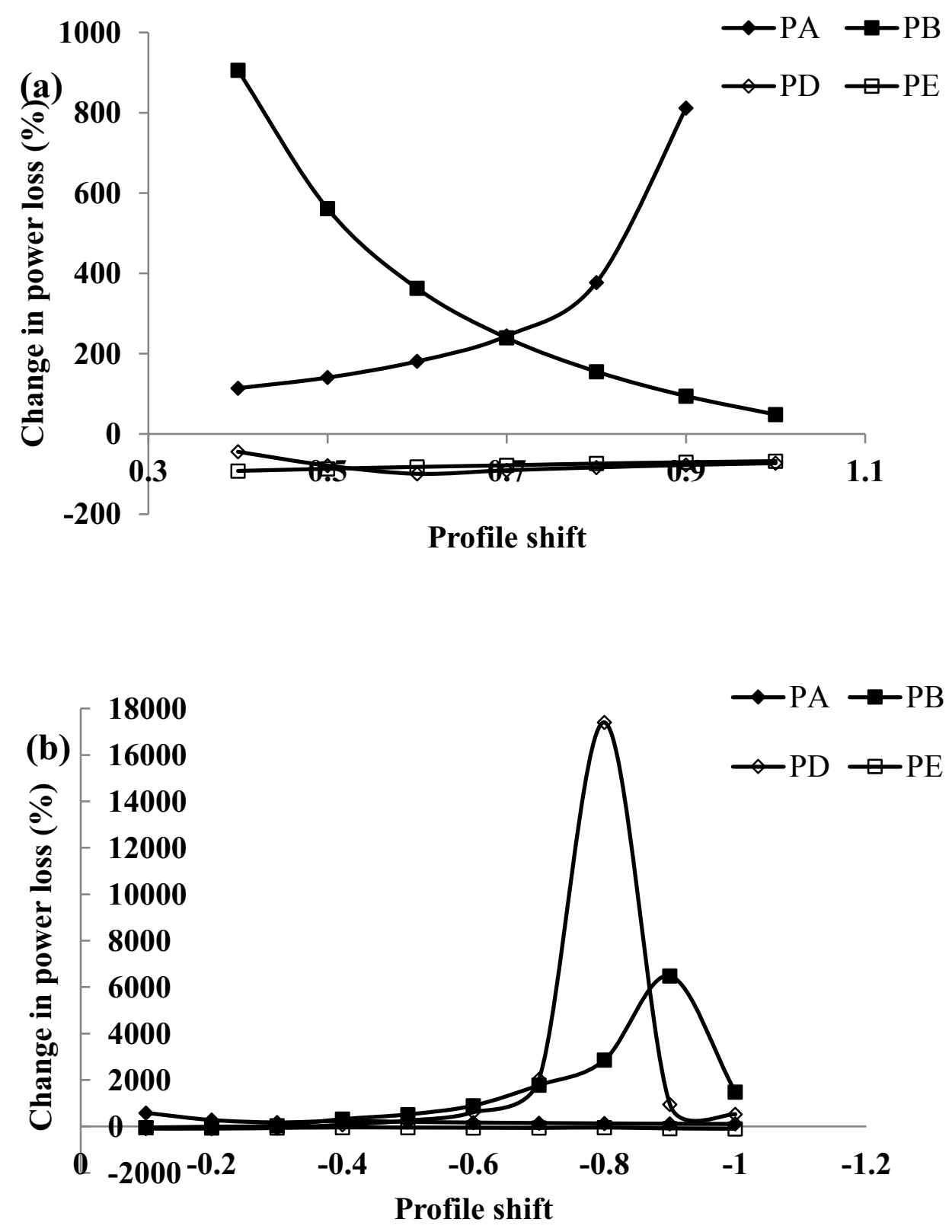

Fig. 10. Plot of percentage change in power loss along length of path of contact for lower range of pressure angle: a) 96 and 100 tooth-sum b) 100 and 104 tooth-sum.

Fig. 10(a) shows the percentage difference in power loss at different points along the length of path of contact for 96 tooth-sums and 100 tooth-sums for lower range of pressure angle. In case of 96 tooth-sums the profile shift will vary from 0.4 to 1.9 whereas for 100 tooth-sums the profile shift will vary between -1 to 1 . The percentage change in power loss has been calculated by considering the range of profile shift from 0.4 to 1 which is common in both the cases. At point A negative alteration in tooth-sum has 2.66 times less power loss as compared to standard tooth-sum gearing. Similarly, negative altered tooth-sum gearing at different points B, 
$\mathrm{D}$ and $\mathrm{E}$ the power loss is $3.38,-7.8$ and -7.8 times compared to standard tooth-sum gearing. The percentage changes in power loss of positive altered tooth-sum gearing at different points along A, B, D and E will be 2.15, 14.3, 21.6 and -0.6 times lesser as compared to standard tooth-sum gearing.

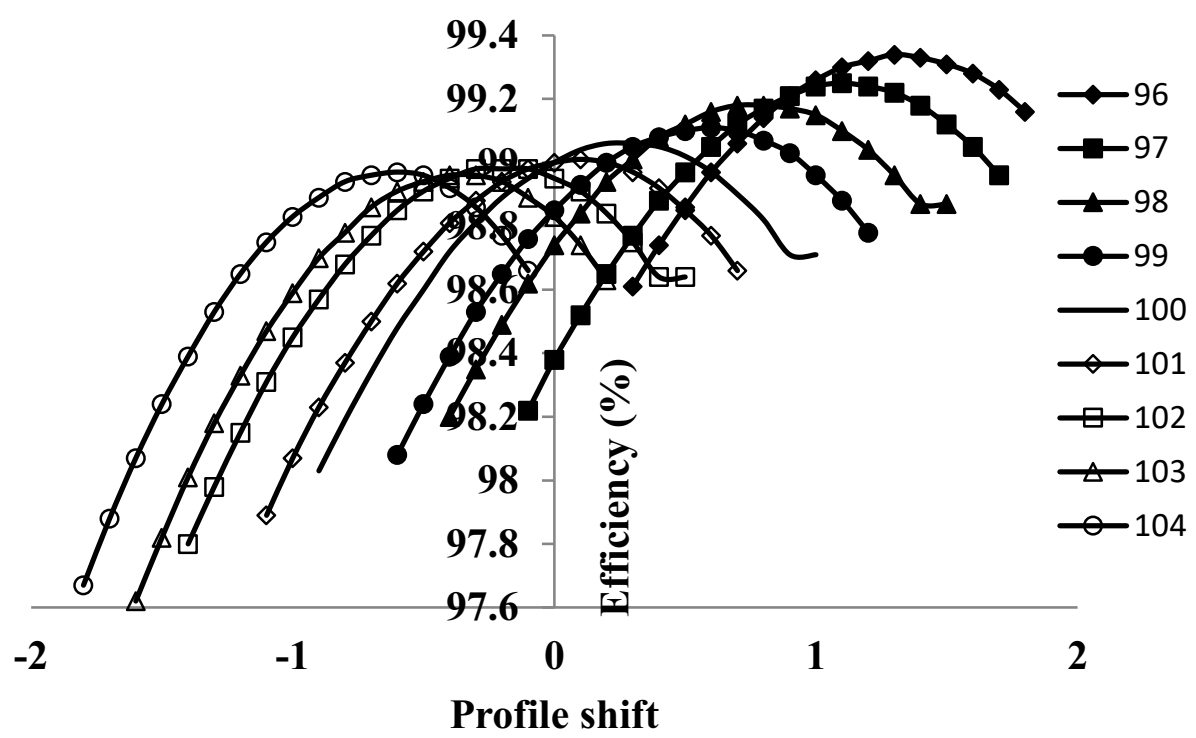

Fig. 11. Efficiency versus profile shift for a tooth-sum of 100 teeth altered by \pm 4 for higher range of pressure angle.

It is observed that the efficiency was more than $98 \%$ (Fig. 11) for both altered tooth-sum gearing and standard gearing. However, efficiency of negative alteration in tooth-sum is slightly more compared to standard and positive alteration in tooth-sum due to reduction in power loss. Also, it is noticed (Table 2) that the efficiency in case for higher range of pressure angle is more as compared to lower range of pressure angle.

Table 2. Comparison of maximum efficiency for higher and lower range of pressure angle for altered toothsum gearing.

\begin{tabular}{|c|c|c|c|c|}
\hline \multirow{2}{*}{$\begin{array}{c}\text { Altered tooth- } \\
\text { sum }\end{array}$} & \multicolumn{2}{|c|}{$\begin{array}{c}\text { For higher range of pressure } \\
\text { angle }\end{array}$} & \multicolumn{2}{c|}{$\begin{array}{c}\text { For lower range of pressure } \\
\text { angle }\end{array}$} \\
\cline { 2 - 5 } & Profile shift $\mathrm{X}_{1}$ & Efficiency \% & Profile shift $\mathrm{X}_{1}$ & Efficiency \% \\
\hline $\mathbf{9 6}$ & 1.3 & 99.34 & 1.4 & 99.31 \\
\hline $\mathbf{1 0 0}$ & 0.2 & 99.06 & 0.3 & 98.79 \\
\hline $\mathbf{1 0 4}$ & -0.6 & 98.97 & -0.5 & 98.48 \\
\hline
\end{tabular}

\section{Conclusions}

The sliding power loss computed for altered tooth-sum operating between a specified center distance has been studied. From this analysis it is observed that the sliding power loss in case of negative altered tooth-sum gearing is less as compared to standard and positive altered tooth-sum gearing. Also, the efficiency observed in case of negative altered tooth-sum gearing is more as compared to standard and positive altered tooth-sum gearing. Efficiency observed in case of higher range of pressure angle is slightly more as compared to lower range of pressure angle. 


\section{References}

1. Fakher, Chaari., Manel, ben, Romdhane., Walid, baccar., Taher, fakhfakh., and Mohamed, haddar., Windage power loss in spur gear sets, Wseas transactions on applied and theoretical mechanics, 7(2), 159-168, (2010).

2. Satya, Seetharaman., and Ahmet, Kahraman., A windage power loss model for spur gears, Tribology transactions, Society of tribology and lubrication engineers, Taylor and Francis, 54(4), 473-484, (2010).

3. Wang, B., Lu, Z., J, Chen, X. B., Wang, P., Luo, W., and Xu, h., Modelling and analysis of dynamic efficiency of manual transmission/reducer, Intl. J. of Auto. Tech. 16(3), 417-426, (2015).

4. James, Kuria., and John, Kihiu., Prediction of overall efficiency in multistage gear train, World academy of science, Engg and Tech, 5(2), 50-56, (2011).

5. Chakrit, yenti., surin, phongsupasamit., and chanat, ratanasumawong., Analytical and experimental investigation of parameters affecting sliding loss in a spur gear pair, Engg J. 17(1), 79-93, (2013).

6. Franco, Concli., and Carlo, Gorla., Analysis of the oil squeezing power losses of a spur gear pair by mean of CFD simulations. Proceedings of the 11th biennial conference on engineering systems design and analysis, ESDA2012, July 2-4, Nantes, France, 1-8, (2012).

7. Miguel, Pleguezuelos., Jose, I, Pedrero., and Miryam, B, Sanchez., Analytical expressions of the efficiency of standard and high contact ratio involute spur gears, Mathematical problems in engineering, Hindawi Publishing Corporation, 1-14, (2013).

8. Chang, l., yeau-ren, jeng., and pay-yau, huan., Modeling and analysis of the meshing losses of involute spur gears in high speed and high load conditions, J. of Tribo., ASME, 135(1), 1-11, (2013).

9. Vijay, Kumar, Karma., and Ram, Kumar., Comparison between experimental and theoretical investigation of power losses of single stage gear system, Engg, Indian J. of research, 2(8), 107-110, (2013).

10. Chaari, F., Kantchev, G., and Haddar, M., Modelling the mechanical efficiency of a spur gear system, proceedings of the ICE-Engineering and computational mechanics, 163(2), 8390, (2010).

11. Abdelilah, Lasr., Lahcen, Belfal., Brahim, Najji., and Bernard, Mushirabwoba., Pressure estimation of the trapped and squeezed oil between teeth spaces of spur gears, Applied mathematical sciences, 8(107), 5317-5328 (2014).

12. Fernandes, C, M, C, G., Marques, P, M, T., Martins, R, C., and Seabra, J, H, O., (2015). Influence of gear loss factor on the power loss prediction, Mechanical sciences, 6 (2015), 81-88 (2015).

13. Luis, Magalhaes., Ramiro, martins., Cristiano, Locateli., and Jorge, Seabra., (2010). Influence of tooth profile and oil formulation on gear power loss, Tri. Intl, 43(10), 18611871.

14. Petra, Heingartner., and David, Mba., Determining power losses in helical gear mesh, Gear technology, 33-37, (2005).

15. Anderson, N, E., and S, H, Loewenthal., Spur gear system efficiency at part and full load, Technical report 79-46, NASA technical paper 1622 (1980).

16. Hutchings, I. M., Tribology: friction and wear of engineering materials, Ed. ButterworthHeinemann, oxford, 58-76, (1992).

17. Krishnakumari, A., Elaya, perumal, A., and Panda, R. C., Prediction for condition monitoring of wear and film thickness in a gear box, Engg. Mechanics, 19(6), 393-405, (2012). 
18. Muraro, M. A., Koda, F., Reisdorfer, Jr, U., and silva, C. H. D., The influence of contact stress distribution and specific film thickness on the wear of spur gears during pitting tests. J. of Brazilian soc. of mech. sciences and Engg, 34(2), 135-144, (2012). 